\title{
Composite polypropylene polymer materials that work in contact with raw cotton
}

\author{
Olim Eshkobilov ${ }^{*}$, and Giyas Gulyamov ${ }^{2}$ \\ ${ }^{1}$ Karshi Engineering-Economic Institute, Karshi, Uzbekistan \\ ${ }^{2}$ State Unitary Enterprise "Fan va tarakkiyot" at Tashkent state technical university named after Islom \\ Karimov, Tashkent, Uzbekistan
}

\begin{abstract}
Physicomechanical and tribotechnical properties of structural composite materials based on thermoplastic polymer and organomineral ingredients operating under friction and wear conditions during contact with pulp (raw cotton) have been investigated. The regularities of changes in the physical, mechanical and tribotechnical properties of structural composite materials during contact interaction with raw cotton were determined, the dependence of their properties on the type and content of graphite, mineral and fibrous fillers in structural composite materials was studied. It has been established that the nature and structure of fillers has a certain effect on the physical and mechanical properties of composite materials based on polypropylene. At the same time, fiber-filled compositions have the highest mechanical strength. It was also found that when mineral fillers are introduced into composite polymer materials, their coefficient of friction with raw cotton increases significantly, while the wear rate decreases, except for fillers with a plate structure (kaolin, talc), when used, a decrease in the coefficient of friction is observed. The introduction of carbon-graphite fillers into the composition of composite materials leads to a significant decrease in the coefficient of friction, temperature and static electricity charge in the friction zone with raw cotton. The introduction of fillers with a fibrous structure leads to a significant decrease in the rate of wear of the composites. It provides high strength and resistance of the material under thermomechanical action. Effective compositions of structural composite materials for work under conditions of contact interaction with fibrous mass have been developed, and their physical, mechanical and tribotechnical properties have been investigated.
\end{abstract}

\section{Introduction}

At present, the intensification of the development of cotton growing is of great importance, especially in mechanization and processing of raw cotton, which occupies a special place in the economy of Uzbekistan. Increasing the efficiency of cotton growing can be achieved through the comprehensive mechanization of all processes, from harvesting to cotton processing, increasing the efficiency and productivity of the machines and mechanisms

*Corresponding author: polegon11@mail.ru 
used while maintaining the natural indicators of raw cotton. One of the directions for solving the problem is developing new effective structural composite polymer materials and their use in cotton machines and mechanisms.

The details of the working bodies of cotton machines are operated under difficult loading conditions. when interacting with raw cotton in compacted riots. Structural composite polymer materials increase their performance and ensure minimal damage to cotton fiber while maintaining its natural properties. Also, the development and use of new structural composite polymeric materials provide an increase in the productivity of machines, a decrease in power consumption, and excludes the possibility of cotton ignition and fiber winding on the surface of the peg parts.

In most of the well-known works, the development of antifriction-wear-resistant composite polymer materials was carried out without taking into account studies of the influence of the nature, type, content of polymer and fillers in composites, and these works did not investigate the processes of temperature change and the formation of static electricity during contact interaction in systems "polymer-cotton" and "composite-cotton", which made it impossible to obtain materials with a low coefficient of friction and high wear resistance.

Based on the molecular-mechanical theory of friction, a molecular-mechano-electrical theory was developed that describes the processes occurring during the contact interaction of a material with a fibrous mass.

The aim of this work is to study the physical, mechanical and tribotechnical properties (friction coefficient, wear rate, temperature and static electricity charge in the friction zone) of new structural composite materials with antifriction properties and high wear resistance based on a thermoplastic polymer and organomineral fillers for operation under conditions contact interaction with pulp-raw cotton.

\section{Materials and Methods}

We investigated structural composite materials based on thermoplastic polymerpolypropylene (TU 6-05-1105-80) grade 05P10/020 - with mineral (ground talc - GOST 879-52, kaolin - GOST 6138-81, wollastonite, chalk - GOST 17498-85), fibrous (fiberglass - TU6-11-191-90, cotton lint - GOST 9849-74) and carbon-graphite (graphite - GOST 5261-85, soot - TU 5-52 ATG-70) fillers. These fillers differ in shape and particle size: granular (soot), lamellar and flaky (graphite, kaolin, talc, wollastonite), fibrous (fiberglass, cotton lint). The average particle size of the filler should be between 1-50 microns.

The choice of fillers is due to the following:

- graphite and carbon black improve the thermal and electro-physical properties of the composite;

- fiberglass and cotton lint give the high strength material and increase resistance to thermomechanical effects due to reinforcement;

- talc, kaolin, chalk and wollastonite are available and inexpensive compared to other materials, which makes it possible to reduce the cost of structural composite materials with a polyolefin matrix.

To study the antifriction properties and wear resistance of polymer compositions operating under friction conditions, raw cotton of the 1st grade of a manual collection with a moisture content of $8-20 \%$, contamination of $1-3 \%$ at an average density was used as a counterbody laying $170-180 \mathrm{~kg} / \mathrm{m}^{3}\left(50-70 \mathrm{~kg} / \mathrm{m}^{3}\right.$ - loosened free-lying raw cotton, $240-250$ $\mathrm{kg} / \mathrm{m}^{3}$ packed raw cotton). Such values of moisture and contamination of raw cotton are the most typical for the operation of the harvesting network of the cotton gin industry.

The method of obtaining structural composite materials and manufacturing samples was as follows. Composite materials were obtained by mixing organomineral fillers in a mixer 
with a movable cup, which was then mixed with a polymer binder in a two-chamber mixer with electric heating. The grinding was carried out after their preliminary mixing in a given proportion on a dismembrator unit, the principle of operation of which is based on impactsplitting and abrasion effects. The rotation speed of the working body of the dismembrator was $1500 \mathrm{rot} . / \mathrm{min}$.

Material with a particle size of up to $15 \mathrm{~mm}$ was continuously poured into the hopper of a working dispenser, from where it fell into a hollow tube and was pre-crushed under the impact of a rotating shaft. In this case, the material continuously moved in the direction of the stationary and rotating discs, in the zone of which it is crushed.

The physical and mechanical properties of structural composite materials were studied using generally accepted standard methods, and the complex of tribotechnical properties in interaction with raw cotton was studied on a disk tribometer.

\section{Results and Discussion}

As a result of the studies carried out, the effect of carbon-graphite, mineral and fibrous fillers on the physical, mechanical and tribotechnical properties of polypropylene under conditions of contact interaction with raw cotton was studied. The breaking stress $\left(\sigma_{\mathrm{b}}\right)$ and modulus of elasticity $(\mathrm{E})$ in bending, hardness $(\mathrm{HB})$ and impact strength $\left(\sigma_{\mathrm{i} . \mathrm{s}}\right)$. This is because the efficiency and durability of composite polymer pegs of working bodies of cotton machines and mechanisms are mainly determined by these indicators of the splitting material and the tribotechnical properties during friction with raw cotton. As is known, $\sigma_{b}-$ characterizes the resistance of a material to fracture at sufficiently high deformation rates; $\mathrm{E}$ - is a characteristic necessary in assessing the strength of a material and determines the nature of the contact frictional interaction and the actual contact area (ACA) during elastic contact of rubbing surfaces; $\sigma_{\text {i.s. }}$ - is one of the main characteristics of the material that determines the structural strength; $\mathrm{HB}$ is an important characteristic of the material that determines the ACA in plastic contacting.

Figures 1-8 show the results of a study of the physical-mechanical and tribotechnical properties of structural composite materials based on polypropylene, depending on the type and content of mineral, fibrous and carbon-graphite fillers.

As can be seen from Fig. 1, the introduction of mineral, fibrous and carbon-graphite fillers - fiberglass, cotton lint, wollastonite, and chalk up to 20-30 m.p. including leads to an increase in the breaking stress during bending of composite polypropylene materials (CPPM) to a maximum. 


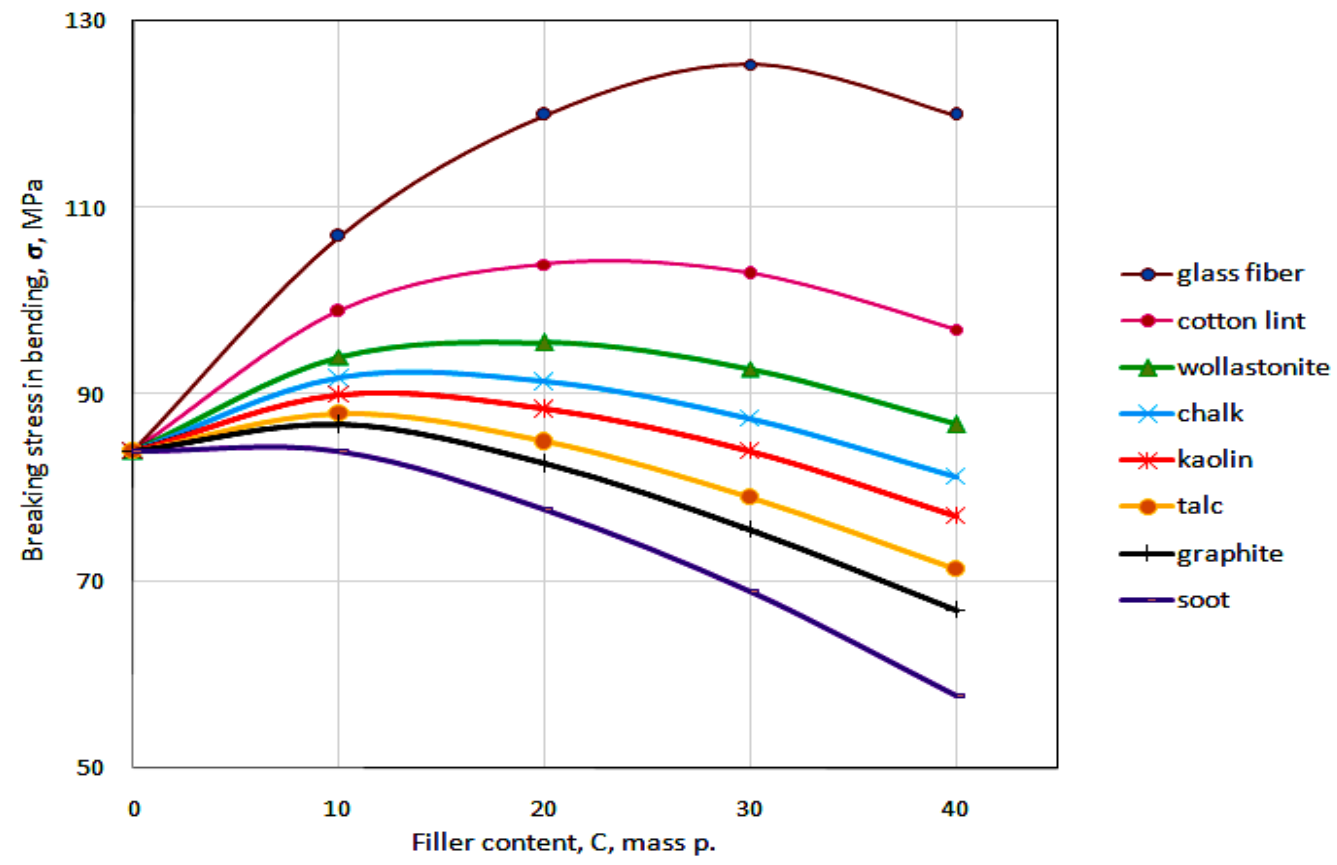

Fig. 1. Dependences of the breaking stress in bending of CPPM on the type and content of mineral, fibrous and carbon-graphite fillers.

A further increase in the content of these fillers is accompanied by a gradual decrease in the values of the breaking stress in bending. With the introduction of such mineral ingredients as talc, kaolin and, especially, carbon-graphite fillers - soot and graphite in polypropylene, the breaking stress during bending decreases with an increase in their content.

However, the magnitude of the breaking stress in bending remains rather high for compositions filled up to 15-20 m.p. including talc, kaolin and up to 5-10 m.p. including soot and graphite.

In general, the increase in flexural strength up to a certain filler content appears to be related to its accumulation in the interspherolite regions, where the filler enters during crystallization. The decrease in the strength of the compositions at high fillings is apparently caused by the fact that the presence of a large amount of filler between the polymer macromolecules somewhat complicates the energy of their intermolecular interaction, accelerating the process of decomposition of the composition.

The impact strength of CPPM with an increase in fibreglass content, lint and wollastonite up to 30 m.p., cement up to 10-15 m.p. also increases and then decreases. With the introduction of other fillers, the impact strength value gradually decreases with increased filler content (Figure 2). 


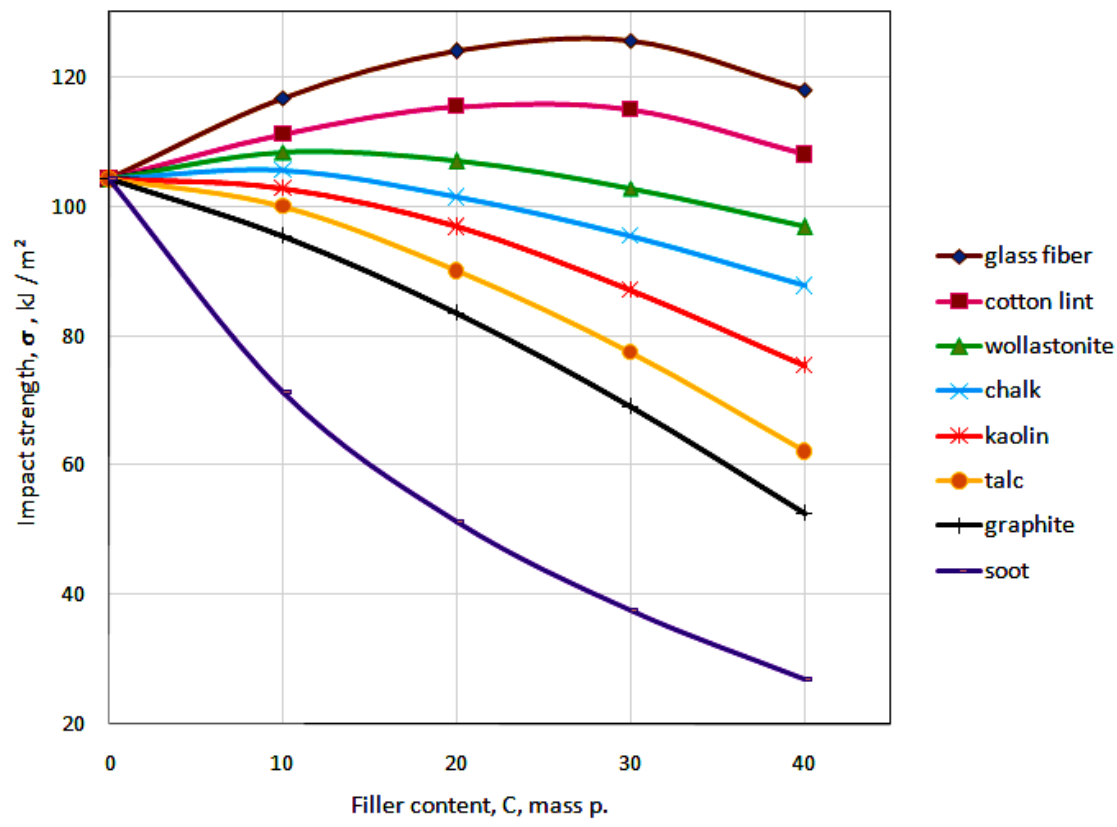

Fig. 2. Dependences of the impact strength of CPPM on the type and content of fillers.

The hardness of CPPM (Fig. 3) with the introduction of fiberglass, lint, cement, kaolin is up to 30 m.p., talc, soot and graphite up to 10-15 m.p. increases and then decreases.

The flexural modulus of CPPM (Fig. 4) gradually increases with an increase in the content of mineral fillers.

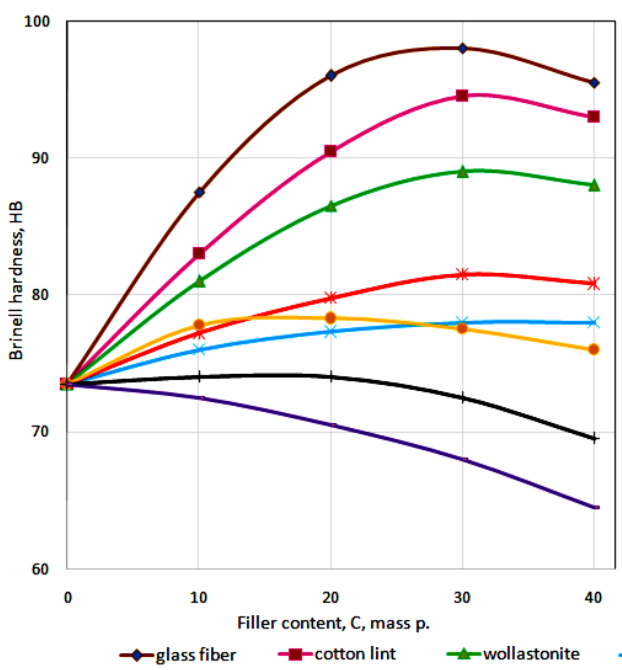

Fig. 3. Dependences of Brinell hardness of CPPM on the type and content of fillers

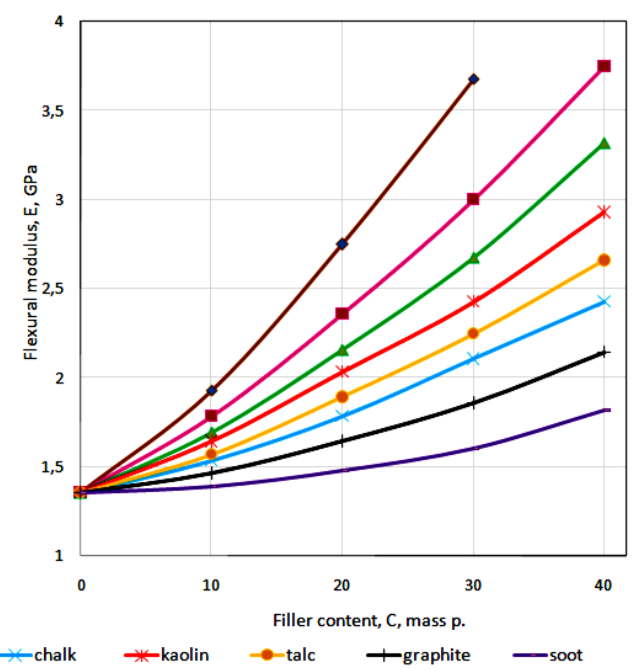

Fig. 4. Dependences of the elastic modulus in bending of CPPM on the type and content of fillers.

Comparing the results of measurements of the main indicators of the strength of CPPM shows that the values of the breaking stress in bending, impact toughness, hardness and elastic modulus in bending depend on the type and content of mineral, fibrous and carbon- 
graphite fillers. In this case, the greatest strength is possessed by a polypropylene composition filled with 30-40 m.p., including fiberglass. For example, when adding fillers of fiberglass, talc, soot, graphite, kaolin, chalk, wollastonite and cotton lint up to $10 \mathrm{~m} . \mathrm{p}$.

Such an increase in the flexural strength and impact toughness of the polypropylene composition filled with fiberglass and cotton lint is explained by the reinforcing ability of the fiber filler and the high strength of fiberglass. A decrease in properties when the content is more than 30 m.p., including fiberglass and cotton lint, is explained by the lack of wetting of the fibrous fillers by the polymer matrix. In places where the fillers are not wetted, air bubbles appear, which are local points of concentration of internal stresses in the matrix, i.e. centres of the destruction of the polymer composition.

The addition of talc to polypropylene insignificantly changes the flexural strength of composite materials. This is due to the scaly shape of this filler and its high specific surface area.

It is known that the filling of polymers with carbon black leads to an increase in the rigidity of the material and the modulus of elasticity; therefore, this leads to a decrease in the toughness of the composition. The results of the experimental data confirm this position.

In general, the decrease in the strength of CPPM ls at high fillings is apparently caused by the acceleration of the processes of destruction of the polymer composition. Dangerous defects appear in composite materials.

A change in the hardness value with a low content of mineral, fibrous and carbongraphite fillers occurs due to a change in the rigidity of the polymer-filler system. An increase in hardness with a small amount of filler is due to a change in the degree of structural ordering of polypropylene, and a decrease in the hardness of a composition with a further increase in the content of fillers is apparently because shear deformation destroys the structures of their fillers, which, moreover, however, is not capable of active interaction with the polymer

Therefore, upon deformation, the contacts between the filler particles are easily destroyed, and in the absence of their interaction with the polymer matrix, the entire system is weakened.

A decrease in the impact strength of CPPM is obviously explained by the fact that an increase in the filler content leads to the appearance of large internal stresses that reduce the strength of bonds between the polymer matrix and filler particles, the appearance of dangerous defects in the form of microcracks, pores, etc.

Thus, the analysis of experimental data shows that the nature and structure of fillers has a definite effect on the physico-mechanical properties of composite materials based on polypropylene. At the same time, the fibrous-filled compositions have the greatest mechanical strength.

Figures 5-8 show the results of a study of the tribological properties of the investigated CPPM with raw cotton, depending on the nature and content of various fillers. 


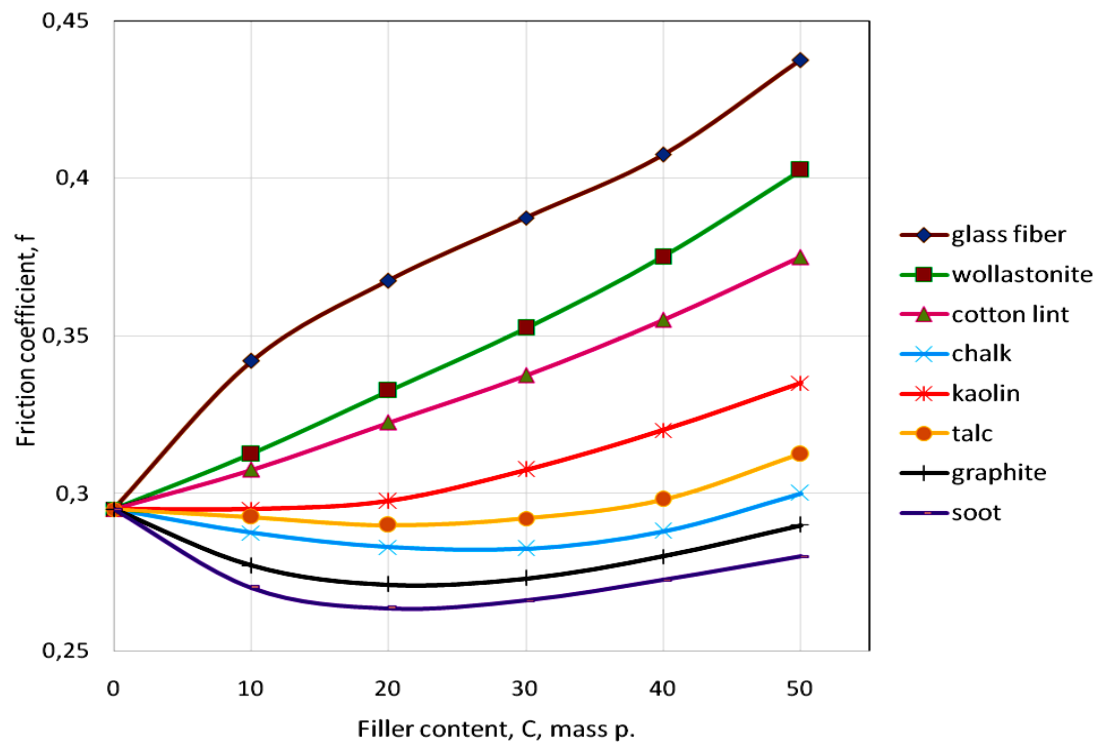

Fig.5. Dependences of the coefficient of friction of CPPM with raw cotton $(\mathrm{P}=0,02 \mathrm{MPa}, \mathrm{V}=2 \mathrm{~m} / \mathrm{s}$, $\mathrm{W}=8,2 \%)$ on the type and content of fillers.

As seen from Fig. 5, with the introduction of graphite, soot, kaolin, talc and wollastonite into the composition of polypropylene, a decrease in the coefficient of friction of the polypropylene composition with raw cotton is observed. The introduction of the remaining fillers causes an increase in the coefficient of friction. Also, due to the high viscosity of the melt of the polypropylene composition, the critical values of the content of the filler are reduced. So, for example, the minimum coefficient of a polypropylene composition is observed at 15-20 m.p. including graphite and soot. With an increase in the content of fiberglass, cotton lint, chalk, wollastonite, talc and kaolin, the coefficient of friction of composite polyethylene materials with raw cotton increases.

A decrease in the coefficient of friction of CPPM filled with talc and kaolin is associated with their lamellar structure and fine dispersion. Composite materials filled with soot and graphite have a relatively low thermal conductivity.

An increase in the coefficient of friction of composite materials with raw cotton at high filler contents is associated with an increase in their surface roughness due to aggregation of the filler and a decrease in the physical and mechanical properties of the material due to insufficient wetting of the filler particles by the polymer matrix.

Analysis of the results of studying the change in the intensity of linear wear of composite polypropylene materials during friction with raw cotton, depending on the content of the filler (Fig. 6), shows that with an increase in the content of talc and kaolin to 10-20 m.p. the wear rate remains almost unchanged, despite a slight increase in the friction coefficient (Fig. 5). The introduction of graphite and soot increases the wear rate, which correlates with a change in the coefficient of friction. An increase in the wear rate of composite materials with an increase in the content of soot and graphite is explained by a decrease in the hardness and embrittlement of the material.

In addition, with an increase in the content of fiberglass, wollastonite, cement and kaolin, the wear rate of composite materials first decreases, then, after passing through a minimum, it increases. Moreover, the minimum and its value, depending on the content and nature of the filler, are different.

Composite polymer materials filled with wollastonite, cotton lint and fiberglass are highly resistant to wear. For materials filled with fiberglass and cotton lint, the wear rate 
decreases to a minimum value and the friction coefficient increases with an increase in their content.

As a result of the studies carried out, fillers were established, with an increase in the content of which the coefficient of friction and the intensity of wear of the composition during friction with raw cotton were reduced.

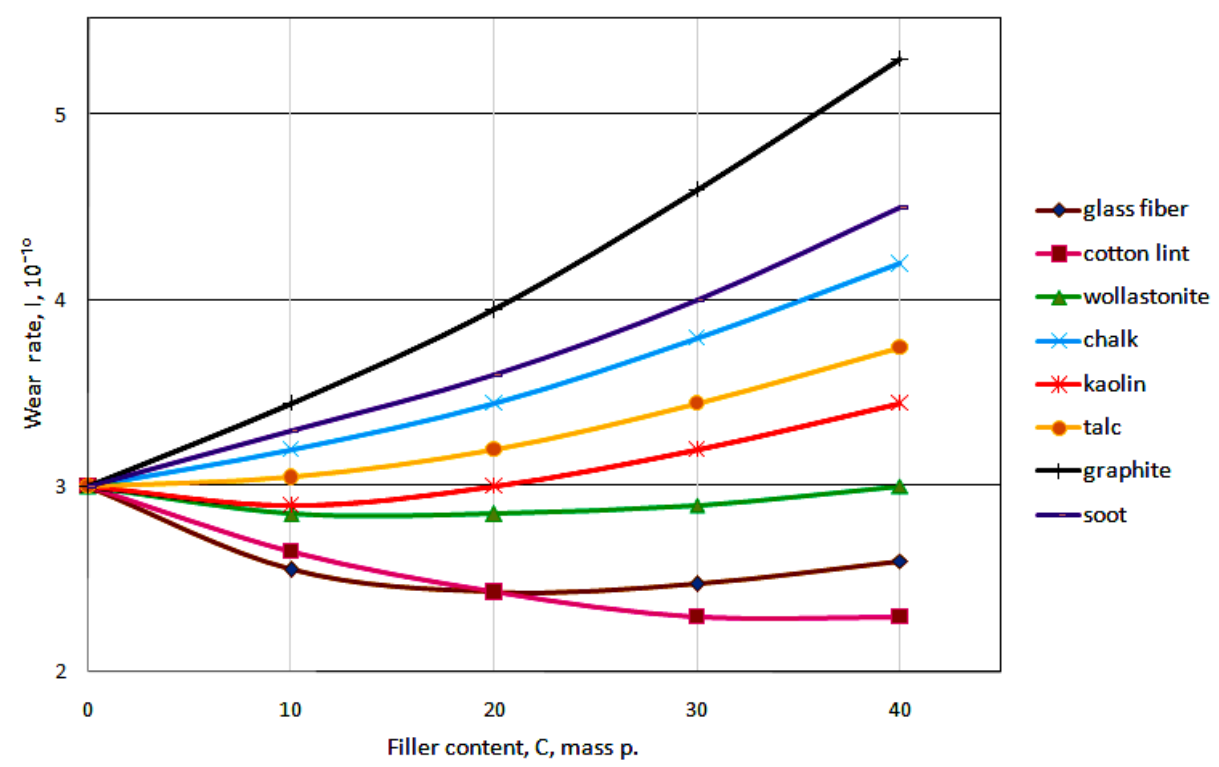

Fig.6. Dependences of the linear wear rate of $\mathrm{CPPM}$ with raw cotton $(\mathrm{P}=0,02 \mathrm{MPa}, \mathrm{V}=2 \mathrm{~m} / \mathrm{s}$, $\mathrm{W}=8,2 \%)$ on the type and content of fillers.

It was found that the following filler contents are optimal for the minimum friction coefficient of CPPM: soot and graphite 5-25 m.p., talc 10-30 m.p., kaolin 10-30 m.p., chalk $10-40$ m.p.

For the minimum value of the wear rate of composite polymer materials during rubbing with raw cotton, the optimal filler content for polypropylene and polyethylene compositions is 5-30 m.p. including fiberglass and chalk, 5-25 m.p. including kaolin and talc.

The study of the friction coefficient and the wear rate of composite polymer materials does not make it possible to explain the interaction process in the polymer-cotton system without the results of studying the temperature and static electricity charge in the friction zone, which can lead to undesirable phenomena, such as a decrease in the performance of machines, a fire, etc.

In this regard, research has been carried out to study the appearance of temperature and static electricity in the friction zone.

As seen from Fig. 7, a polypropylene composition by friction with raw cotton, with the introduction of fillers of graphite, soot and wollastonite, the temperature in the friction zone decreases, and with the introduction of fillers of cotton lint, fiberglass, talc and kaolin, an increase in temperature is observed. 


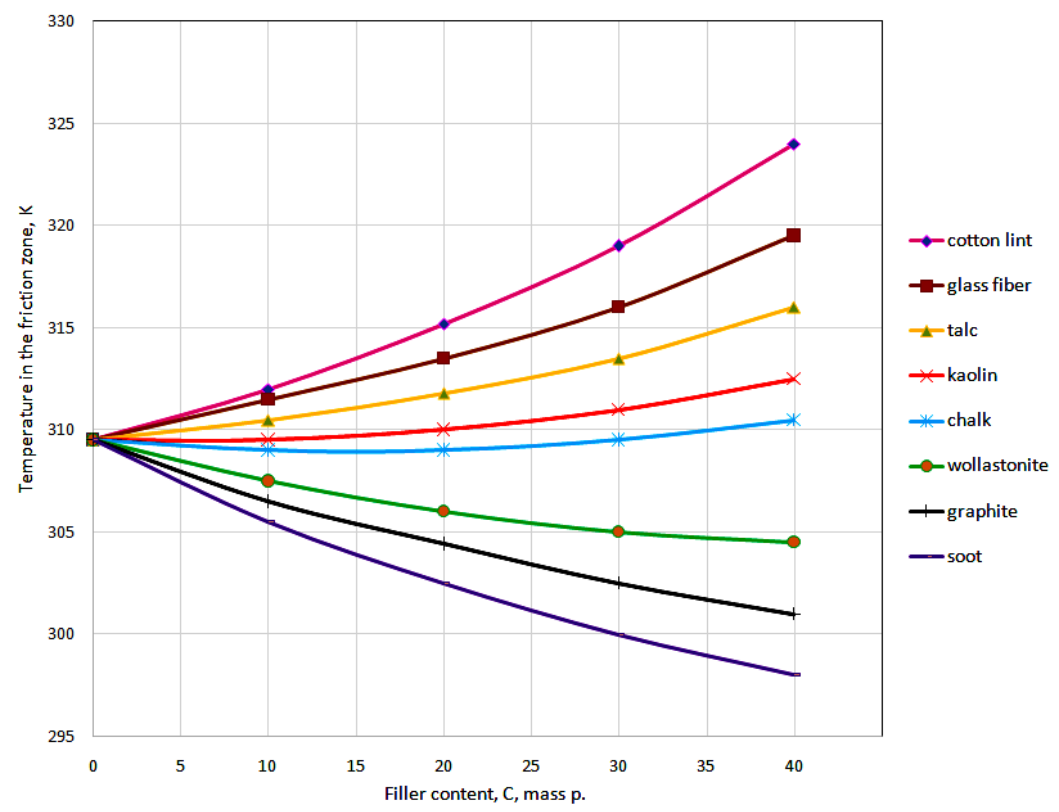

Fig.7. Dependences of temperature in the friction zone of $\mathrm{CPPM}$ with raw cotton $(\mathrm{P}=0.02 \mathrm{MPa}, \mathrm{V}=2$ $\mathrm{m} / \mathrm{s}, \mathrm{W}=8.2 \%$ ) of the type and content of fillers.

From the results of experimental studies (Figure 8) it can be seen that in the process of friction, electric charges arise and accumulate. As a result, the tension and electric forces in the double electric layer increase, which possibly, leads to an increase in the total frictional force.

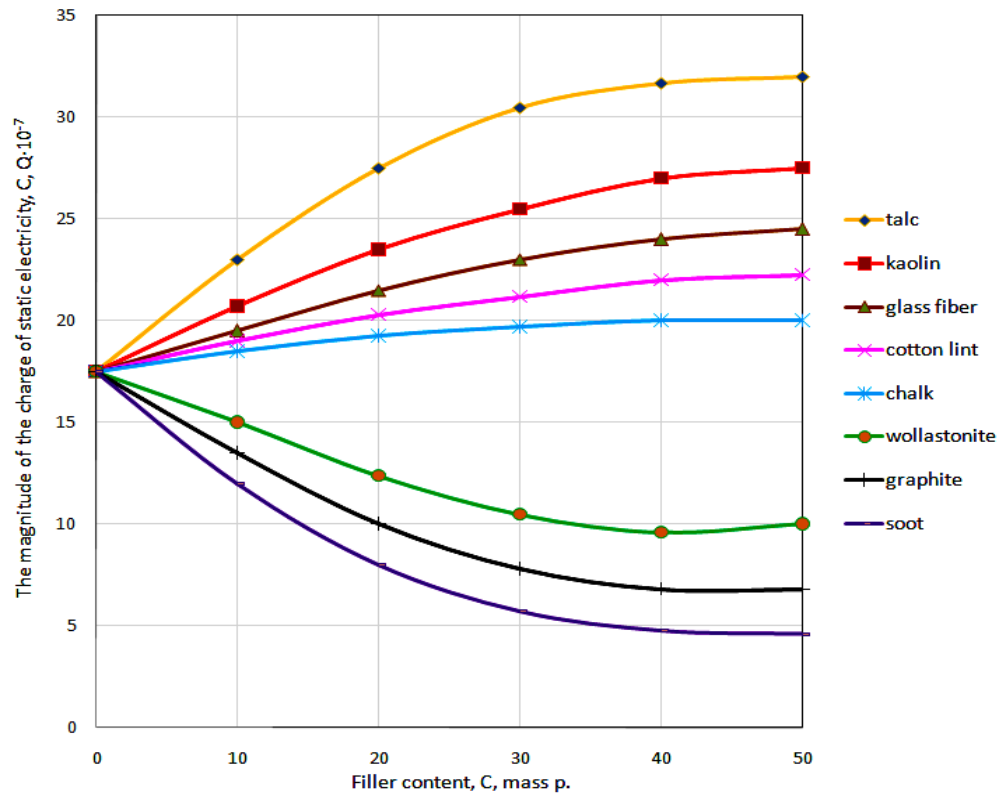

Fig.8. Dependences of the magnitude of the charge of static electricity during friction of CPPM with raw cotton $(\mathrm{P}=0,02 \mathrm{MPa}, \mathrm{V}=2 \mathrm{~m} / \mathrm{s}, \mathrm{W}=8,2 \%)$ of the type and content of fillers. 
With an increase in the content of talc and kaolin in polypropylene composites, the degree of their electrification increases, the value of charges at $40 \mathrm{~m}$.p. is equal to $31,5 \cdot 10^{-7}$ and $35,6 \cdot 10^{-7} \mathrm{C}, 26,7 \cdot 10^{-7}$ and $31,3 \cdot 10^{-7} \mathrm{C}$, respectively. This is explained, apparently, by the fact that talc significantly improves the electrical insulating properties of the compositions,

Filling the composition with graphite and soot causes a strong decrease in the static electricity charge when rubbed with raw cotton.

The addition of talc, kaolin, fiberglass, cotton lint, chalk to the polypropylene composition increases the amount of charge, while the addition of graphite, soot and wollastonite decreases it. This is due to the different effect of mineral fillers on the electrical conductivity of polymer compositions. With an increase in the content of mineral fillers of conductors and semiconductors, the number of contacts between particles increases, and the surface of the contacts increases. As a result, the electrical and thermal conductivity of composite polymer materials increases. An increase in the content of talc and kaolin also causes an increase in contacts between filler particles, but this leads to a slight increase in electrical resistance and a decrease in the thermal conductivity of composite material.

Filling polypropylene compositions with wollastonite causes a decrease in the amount of static electricity when rubbed with raw cotton. Wollastonite, having a higher electrical conductivity than other fillers, somewhat reduces electrification, which is associated with a higher conductivity and charge leakage in composite polymer materials filled with wollastonite.

\section{Conclusions}

It has been shown that the physical, mechanical and strength properties, as well as the coefficient of friction, the rate of wear, the magnitude of the charge of static electricity, and the temperature in the friction zone of CPPM with raw cotton, depend on the type, nature and content of fillers.

It has been established that the introduction of carbon-graphite fillers into the composition of structural CPPM leads to a significant increase in the physical, mechanical and strength properties, a decrease in the friction coefficient, temperature and the magnitude of the static electricity charge in the friction zone with raw cotton.

The introduction of mineral fillers significantly increases their strength properties, the coefficient of friction of the CPPM with raw cotton, the temperature and the amount of static electricity in the friction zone, and at the same time reduces the wear rate of the composite material. An exception is a composite polymer material with fillers such as talc and kaolin, which have a plate-like structure and reduce the coefficient of friction polymer composite.

The efficiency of decreasing the wear rate and increasing the strength properties of CPPM increases with the introduction of fillers of a fibrous type, which provide high strength and resistance of the material to thermal effects.

The established regularities of changes in the properties of structural CPPM during frictional interaction with raw cotton on the type and content of fillers are consistent with the molecular-mechanical-electrical theory of friction, based on which it is possible to develop promising structural composite materials for operation in conditions of contact interaction with raw cotton allowing the manufacture of parts of the working bodies of machines and mechanisms. 


\section{References}

1. Negmatov S.S., Abed N.S., Gulyamov G., Eshkobilov O.Kh. Features of contact interaction of composite polymer materials with raw cotton in the process of friction. IOP Conference Series: Materials Science and Engineering, Volume 1030, VII International Scientific Conference "Integration, Partnership and Innovation in Construction Science and Education" (IPICSE 2020) 11-14th November 2020y, Tashkent, Uzbekistan. doi:10.1088/1757-899X/1030/1/012172. (2020).

2. Negmatov S.S., Abed N.S., Gulyamov G., Eshkobilov O.Kh. Investigation of the effect of temperature and electric charge on the coefficient of friction of a composite material when interacting with raw cotton, Innovative technologies, №3(39)// Karshi, 2020y. pp. 55-59, ( 2020).

3. Negmatov S.S., Abed N.S., Gulyamov G., Tukhtasheva M.N., Eshkobilov O.Kh, Study of the strength properties of antifriction antistatic-heat-conducting composite materials based on polyolefins, Innovative technologies, 4 (40)// Karshi,. pp. 33-37. (2020)

4. Negmatov S.S., Gulyamov G., Eshkobilov O.Kh., Daminov L.O. Anti-friction and wear-resistant composites for automobiles and tractor construction. Automotive and tractor construction, International scientific-practical conference, Belarusian National Technical University. Byelorussia, pp 28-31.(2019)

5. Negmatov S.S., Abed N.S., Gulyamov G., Eshkobilov O.Kh. Installation and methodology for determining of antifrictional properties of antistatic-heat-conducting composite polymeric materials interacting with fibrous mass (cotton-raw), Technical science and innovation// Tashkent, 2.pp 20-23.( 2018)

6. Negmatov S.S., Eshkobilov O.Kh., Abed N.S., Negmatova K.S., Tulaganova V. Theoretical basics of contact interaction of machinery antifriction composite polymer materials with fibrous mass (raw cotton), Advanced Materials Research, Switzerland, pp 160-166.( 2018)

7. Abed N.S., Gulyamov G., Eshkobilov O.Kh. Methods for studying the coefficient of friction of wear of composite polymer materials based on polyolefins, International symposium on innovative scientific conference "Integration and integration of science and education" /International scientific-practical conference/ Tashkent,. -pp. 41-43. (2018).

8. Eshkobilov O.Kh. Ensuring the reliability of operation of parts and assemblies made of engineering polymer materials based on local raw materials, Modern trends in the development of the agrarian complex ,International scientific-practical conference, Caspian Research Institute of Arid Agriculture. -Solenoe Zaymishe, 11-13 мау 2016y. -P. 1301-1304. (2016).

9. Negmatov S.S., Abed N.S., Gulyamov G., Eshkobilov O.Kh, Tukhtasheva M.N. Investigation of the physicochemical mechanism of interaction of the components of antistatic and heat-conducting polypropylene composite materials. The role of chemistry in the development of the economy of Uzbekistan /Republican scientific and practical conference/-SamSU, Samarkand, pp 67-70.(2018).

10. Negmatov S.S., Abed N.S., Gulyamov G., Eshkobilov O.Kh., Tukhtasheva M.N. Methods for studying the tribological properties of antifriction-wear-resistant antistatic-heat-conducting composite polymer materials with fibrous mass, Composite materials, №1// -Tashkent,. pp. 86-89. (2018)

11. Negmatov S.S., Abed N.S., Gulyamov G., Eshkobilov O.Kh., Tukhtasheva M.N. On the problem of developing methodological foundations of the method for studying the properties of anti-friction-wear-resistant antistatic-heat-conducting composite polymer materials operating under conditions of interaction with pulp, Composite materials, 1 . 
Tashkent,. pp 99-100.(2018).

12. Abed N.S., Gulyamov G., Eshkobilov O.Kh. Composites based on functional thermoplastic polymer systems. Modern problems of polymer science, Uzbek-Kazakh Symposium, Institute of Chemistry and Physics of Polymers of the Academy of Sciences of the Republic of Uzbekistan. -Tashkent,.pp 90-92. (2018)

13. Negmatov S.S., Abed N.S., Gulyamov G., Eshkobilov O.Kh. Peculiarities of the mechanism of chemical interaction of polymers with carbon-graphite fillers. Prospects for innovative development of the mining and metallurgical complex, International scientific-practical conference, Tashkent, pp 222-223.(2018).

14. Negmatov S.S., Abed N.S., Gulyamov G., Eshkobilov O.Kh., Tukhtasheva M.N. A device for determining the coefficient of friction of engineering structural materials. Prospects for innovative development of the mining and metallurgical complex /International scientific-practical conference/ Tashkent. pp 304-305.(2018).

15. Abed N.S., Gulyamov G., Eshkobilov O.Kh., Tukhtasheva M.N. Evaluation of the frictional properties of antistatic-heat-conducting composite polymer materials when interacting with raw cotton. International symposium on innovative scientific conference "Integration and integration of science and education", International scientific-practical conference, Tashkent,. pp. 39-41.(2018).

16. Negmatov S.S., Abed N.S., Gulyamov G., Eshkobilov O.Kh., Tukhtasheva M.N. Technological modes of processing of antistatic-heat-conducting antifriction-wearresistant and nanocomposite and nanocomposite polymer materials. Problems of improving the efficiency of modern production and energy and resource conservation /International scientific-practical conference/ Andijan, 3-4 oktober 2018y. pp. 45-48. (2018)

17. Negmatov S.S., Abed N.S., Gulyamov G., Eshkobilov O.Kh. Installation for determining the antifriction properties of antistatic-heat-conducting composite polymer materials. Problems of improving the efficiency of modern production and energy and resource conservation /International scientific-practical conference/ Andijan,. pp 48-52. ( 2018).

18. Negmatov S.S., Gulyamov G., Abed N.S., Eshkobilov O.Kh., Tukhtasheva M.N. Method for determining the values of electrostatic charges and temperatures occurring in the friction zone in the tribosystem «composite-fibrous materials», Composite materials, Tashkent pp 79-81.(2019).

19. Negmatov S.S., Abed N.S., Gulyamov G., Eshkobilov O.Kh., Tukhtasheva M.N. Development of a method for determining the intensity of wear of anti-friction-wearresistant antistatic-heat-conducting composite polymer materials and coatings based on them when interacting with pulp. Composite materials, 2 Tashkenty, pp 7577.(2019)

20. Negmatov S.S., Abed N.S., Gulyamov G., Eshkobilov O.Kh., Tukhtasheva M.N. Installation and method for determining the antifriction properties of antistatic-heatconducting composite polymeric materials interacting with raw cotton, Mechanic problems, 2, Tashkent. pp 66-70. (2019).

21. Negmatov S.S., Abed N.S., Gulyamov G., Eshkobilov O.Kh. Investigation of the influence of carbon-graphite and fibrous fillers on the antifriction properties of polyolefins, Innovative technologies, 3 (35). Karshi. pp 22-26. (2019).

22. Negmatov S.S., Gulyamov G., Abed N.S., Eshkobilov O.Kh., Tukhtasheva M.N. Antifriction-wear-resistant composite polymer materials for engineering. Integrated innovative development of Zarafshan region: achievements, chalenges and prospects, International scientific-practical conference, Navoiy, 27-28 november 2019y. pp 262265.(2019).

23. Negmatov S.S., Gulyamov G., Ulmasov T.U., Abed N.S., Eshkobilov O.Kh., Saidova 
M.M., Bozorboyev Sh.A., Tukhtasheva M.N., Eminov Sh. Investigation of the technological process of contact interaction of surfaces of metal working bodies of machines with raw cotton. Composite materials, 1. Tashkent, pp 120-124.(2020).

24. Tukhtasheva M.N., Negmatov S.S., Gulyamov G., Ulmasov. T.U., Abed N.S., Eshkobilov O.Kh., Saidova M.M., Eminov Sh., Bozorboyev Sh.A., Navruzov F.M. Experimental study of the effect of fibrous fillers on antifriction, wear-resistant, technological properties of polyolefins. Composite materials, 1. Tashkent, pp 125-128. (2020).

25. Negmatov S.S., Gulyamov G., Abed N.S., Eshkobilov O.Kh., Methods for determining the coefficient of friction, temperature and magnitude of electrostatic charge in the friction zone of machine-building structural materials Composite and metal-polymer materials for various industries and agriculture, International UzbekBelarusian Scientific and Technical Conference. State Unitary Enterprise "Fan va tarakkiyot". Ташкент, 21-22-мау 2020y. pp 209-211. (2020)

26. Negmatov S.S., Gulyamov G., Abed N.S., Eshkobilov O.Kh., Sadikova M.M., Tukhtasheva M.N. Study of the influence of the main parameters of a disk tribometer and operating modes of machines on the coefficient of friction of epoxy composites when interacting with raw cotton, Composite materials, 2. Tashkent,. pp 82-85. (2020).

27. Eshkobilov O.Kh.... №FAP 00782 «Disc tribometer» Utility model patent. Agency of intellectual property of the republic of Uzbekistan. -Tashkent, (2012).

28. Eshkobilov O.Kh.... №FAP 01039 «Disc tribometer» Utility model patent. Agency of intellectual property of the republic of Uzbekistan. -Tashkent, (2015). 